\title{
Management of Epidermoid Carcinoma of the Conjunctiva in a Melanoderma Subject in a Secondary Ophtalmology Centre: About a Case
}

\author{
Moro Sidibe1,2*, Abdoulaye Napo ${ }^{2,3}$, Adama Dembele1, Oumar Diallo1, Djonnyjonas Dembele ${ }^{2}$, \\ Mamadou Adama Togo², Kadiatou Ba Koita ${ }^{3}$, Ibrahima Conare ${ }^{2}$, \\ Abdoulaye Nouhoum Coulibaly², Vonor Kokou Benjamin", Moussa Diassana1, \\ Jeannette Traore ${ }^{2}$, Fatoumata N'diaye ${ }^{2}$
}

\author{
${ }^{1}$ Sikasso Regional Hospital, Mali/Alliance for the Development of Community Ophthalmology (ADOC), Bamako, Mali \\ ${ }^{2}$ Alliance for the Development of Community Ophthalmology (ADOC), Bamako, Mali \\ ${ }^{3}$ Institute of Tropical Ophthalmology of Africa, Bamako, Mali/Alliance for the Development of Community Ophthalmology \\ (ADOC), Bamako, Mali \\ ${ }^{4}$ Kara Regional Hospital Center, TOGO \\ Email: ^msidibefr@gmail.com, ${ }^{\star}$ morosidibefr@yahoo.fr
}

How to cite this paper: Sidibe, M., Napo A., Dembele, A., Diallo, O., Dembele, D., Togo, M.A., Koita, K.B., Conare, I., Coulibaly, A.N., Benjamin, V.K., Diassana, M., Traore, J. and N'diaye, F. (2021) Management of Epidermoid Carcinoma of the Conjunctiva in a Melanoderma Subject in a Secondary Ophtalmology Centre: About a Case. Surgical Science, 12, 351-356. https://doi.org/10.4236/ss.2021.1211036

Received: September 22, 2021

Accepted: November 14, 2021

Published: November 17, 2021

Copyright ( 2021 by author(s) and Scientific Research Publishing Inc. This work is licensed under the Creative Commons Attribution International License (CC BY 4.0).

http://creativecommons.org/licenses/by/4.0/ (c) (i) Open Access

\begin{abstract}
We report a case of a unilateral conjunctival neoformation in a 44-year-old female melanoderma subject. It was a conjunctival squamous cell carcinoma (CSC). The risk factor was exposure to sunlight and dust. No HIV or HPV infection was found. The treatment consisted of simple removal of the tumour with a healthy margin of 3 to $4 \mathrm{~mm}$. After a postoperative follow-up of 18 months, there was no recurrence. As CSC is the most common conjunctival malignancy and given the rate of recurrence with the possibility of associated local invasion, early diagnosis with long-term follow-up is necessary.
\end{abstract}

\section{Keywords}

Carcinoma, Conjunctiva, Surgery, Sikasso, Mali

\section{Introduction}

Conjunctival squamous cell carcinoma (CSC) is a malignant tumour of limbal stem cells. It is the invasive stage of squamous neoplasia of the ocular surface with the invasion of the epithelial basement membrane and the lamina propria. Its clinical distinction from other amelanotic tumours is based on certain clinical and especially histological features [1]. Typically, the lesions present as sessile, white or pink "cauliflower" tumours, slightly elevated, or budding, most often 
with ulcerations, and sometimes ruptured on the surface. Although they have a limited relationship with the surrounding healthy tissue, they are accompanied by typical vascularity of multiple capillaries that form the central vascular axis of the lobules and terminate in the glomerular coves, giving them a raspberry appearance [1]. It usually starts from the conjunctiva between the eyelids and then grows and overlaps with the conjunctiva of the eyelid margins. It may or may not invade the cornea [1]. Squamous cell carcinoma is larger and thicker than carcinoma in situ and is more or less covered with keratin. The non-keratinised type must be differentiated clinically from benign papilloma or carcinoma in situ. The bulbar conjunctiva is the most common location, but lesions can form in the fornix of the palpebral conjunctiva and anterior conjunctiva, and in the caruncles. CSC can exist in different clinical forms [1]: the gelatinous form is the most common, and the nodular type develops rapidly, which is associated with a high risk of lymph node metastasis. The diffuse type is usually difficult to diagnose and is similar to chronic conjunctivitis [1]. The leukoplakic type, which raises the question of differential diagnosis with non-invasive OSNN (Ocular Surface Squamous Neoplasia). Mainly the extension of CSC is local, more superficial than deep. It is referred to as horizontal and vertical progression, which can go from the "tree root" to the sclera, explaining the difficulty of complete deep resection and the high frequency of tumour recurrence.

It represents $5 \%$ of all ocular malignancies [2]. It has an incidence of 8.4 per million population [3]. It is a tumour that develops in the elderly population, but younger cases can occur in subjects with Xeroderma pigmentosum [4]. The male sex is most often affected [5] and frequently seen in fair-skinned subjects than in pigmented subjects [6].

We report the case of a 44-year-old female patient with unilateral budding squamous cell carcinoma.

\section{Patient and Observations}

The patient was 44 years old and consulted for the first time for a swelling that had been evolving for 3 months associated with redness, ocular irritation and foreign body sensations.

The ophthalmological examination revealed a visual acuity of 10/10 in both eyes and revealed a nodular, budding, pigmented, vascularised temporal tumour mass in the right eye, measuring approximately $6 \mathrm{~mm}$ in diameter, mobile, no adherent to the deep plane and purely conjunctival (Picture 1: aspect of the tumour from the front and the side). The rest of the anterior segment and the fundus were normal.

All lymph nodes were free, with no pre-tragic or sub-maxillary adenopathy.

The extension work-up, human immunodeficiency virus (HIV) serology and human papilloma virus (HPV) were negative. Magnetic resonance imaging (MRI) and computed tomography (CT) were not available.

Due to the size and appearance of the tumour, a nodular pigmented squamous 

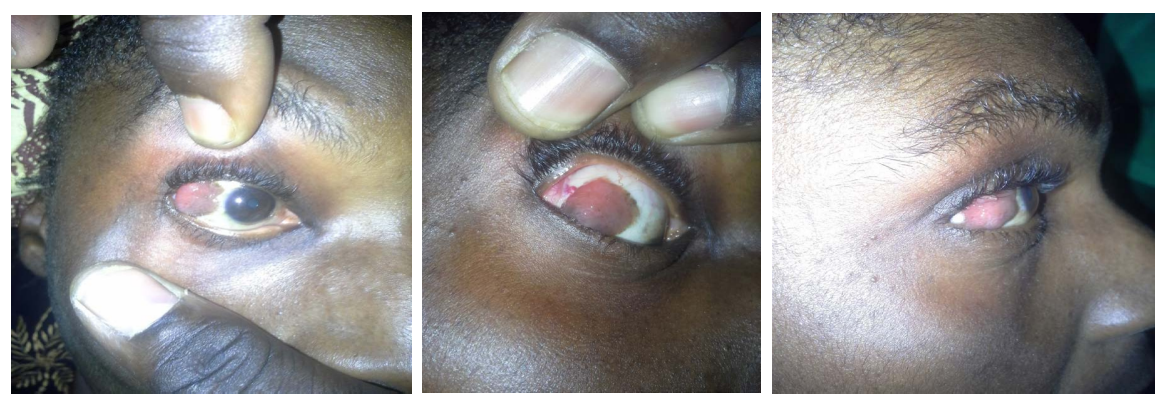

Picture 1. Appearance of the tumor from the front and profile.

cell carcinoma of the conjunctiva was suspected.

Simple excision of the tumour was performed with a healthy margin of about 3 to $4 \mathrm{~mm}$ without adjuvant treatment not available in our secondary ophthalmology centre.

The choice of treatment was motivated by the absence of adjuvant therapies (cryotherapy, radiotherapy, chemotherapy and topical/general immunotherapy), the predictive factors of recurrence which are: advanced age, histological type, positive excision margins, tumour location and lesion size (greater than $10 \mathrm{~mm}$ ). Adjuvant therapy is intended to enhance the success of surgery.

Treatment with local corticosteroids and eyewash was initiated postoperatively.

An anatomopathological examination was requested and the histopathological report concluded an invasive squamous cell carcinoma.

The postoperative follow-up at 6 and 18 months was favourable with a normal appearance of the conjunctiva and transparency of the cornea (Picture 2).

This proves that in the absence of adjuvant treatments such as chemotherapy and others, factors predictive of recurrence and at an early stage that it is possible to perform a simple excision of conjunctival squamous cell carcinoma. However, given the malignant nature of the tumour, surveillance is always necessary.

\section{Discussion}

Classically, carcinomatous lesions present as a sessile, slightly elevated, vegetative or budding white or pinkish "cauliflower" tumour, often ulcerated and sometimes with a fissured surface. Well-limited in relation to the surrounding healthy tissue, they are accompanied by a typical vascularisation consisting of several capillaries that form the central vascular axis of the lobules and terminate in glomerular loops, giving them a raspberry-like appearance [6] [7]. CSC can present in different clinical forms [8]: the gelatinous form is the most common. The nodular form has a rapid course with a high risk of lymph node metastasis. The diffuse form is often difficult to diagnose [9]. The leukoplakic form poses the problem of differential diagnosis with non-invasive OSNN (Ocular Surface Squamous Neoplasia) [1].

Our case was a pigmented nodular form with a purely unilateral conjunctival 

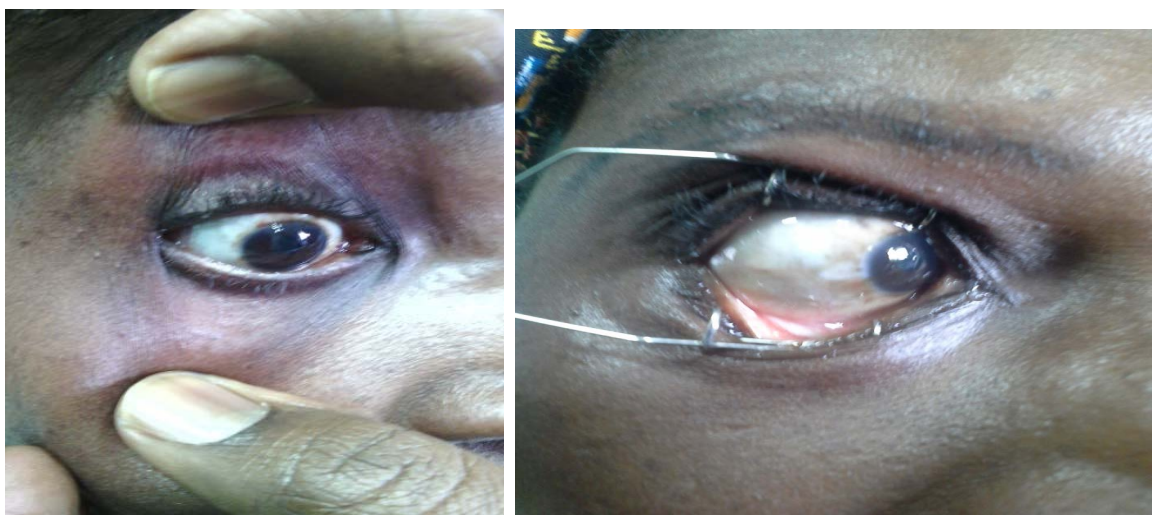

Picture 2. Appearance of the area of excision at 18 months.

location without extension.

Data from the African literature show that CSC is a common malignancy in the tropics. It represents $33.5 \%$ of all malignant tumours of the eye and adnexa [10]. In Ivory Cost, Bereté and al, reported 26 cases in 4 years [11]; in Martinique, 4 cases were reported in 5 years in a mixed population ( 3 melanoderma and 1 Caucasian) [12]. In Senegal Secka S. M. et al., found that it was the second most common ocular cancer with $15.56 \%$ after retinoblastoma and the first conjunctival tumour with $65.56 \%$ [13].

It is a tumour that develops in elderly subjects around the sixth decade, the youngest cases would have occurred in patients with xeroderma pigmentosum [4] [6], whose incidence is $75 \%$.

The various risk factors listed are mainly ultraviolet exposure and immunosuppression [12].

The case we report was 44 years old, melanodermal, female, and could be explained by the combined action of exposure to solar radiation and dust.

Despite the young age of our patient, she was not found to be infected with HIV or HPV and had not been treated with immunosuppressants. Some authors believe that HIV and HPV infections play a role in the genesis of squamous cell carcinoma [14] [15]. Several cases of CSC have been described in HIV positive subjects. BERETE found that $76.92 \%$ of CSC cases were HIV positive with a statistically significant association [11]. In Kenya, the prevalence of CEC was $7.8 \%$ among HIV positive patients [16] and the average age of patients was 38.3 years. In Tanzania, in areas of the AIDS epidemic, an increase in the incidence of CSC was reported, with 10 cases in 1994 and 40 cases in 1997 [17].

When CSC occurs at early ages HIV infection should be investigated [18].

Cases have been reported in patients undergoing long-term immunosuppressive therapy for transplantation [19].

The treatment of CSC is mainly based on surgery, with or without other adjuvant therapies such as cryotherapy, radiotherapy, chemotherapy and topical and systemic immunotherapy. The aim of surgery is to remove the entire tumour with a safety margin of healthy tissue to avoid recurrence [1]. Adjuvant therapy 
is intended to enhance the success of surgery.

For invasive squamous cell carcinomas, excisional biopsy combined with cryotherapy is performed. If the excisional margins are healthy, simple surveillance is performed. If the margins are affected, topical chemotherapy with $0.04 \%$ mitomycin $\mathrm{C}$ and possibly radiotherapy are performed [1].

In our case, we performed a simple excision with a healthy margin of 3 to 4 mm without adjuvant treatment.

The postoperative follow-up was favourable at 6 and 18 months after tumour removal (Picture 2).

The choice of this technique was motivated by the absence of predictive factors for recurrence, which are: advanced age, histological type, positive margins of excision, location of the tumour and size of the lesion (greater than $10 \mathrm{~mm}$ ).

\section{Conclusions}

Conjunctival squamous cell carcinoma is a common malignancy in tropical environments. Prolonged sun exposure is unanimously recognised as a predisposing factor. It most often affects elderly people, but can be seen in young people. This case demonstrates the predisposition of young subjects with pigmented skin but above all reinforces the hypothesis of exposure to sunlight as a favouring factor.

The anatomopathological study of the specimen is the only way to guarantee an early diagnosis of certainty. Early management would reduce recurrence and the need for adjuvant treatment such as cryotherapy, radiotherapy, chemotherapy and topical and general immunotherapy. These adjuvant treatments have a cost and are not always available in our countries.

\section{Conflicts of Interest}

The authors declare that they have no conflict of interest in relation to this article.

\section{References}

[1] Bouguila, H. and Nacef, L. (2014) Conjunctival Tumors. Report of the Tunisian Society of Ophthalmology, 7, 63-69.

[2] Lee, G.A. and Hirst, L.W. (1995) Ocular Surface Squamous Neoplasia. Survey of Ophthalmology, 39, 429-450. https://doi.org/10.1016/S0039-6257(05)80054-2

[3] Kao, A.A., Galor, A., Karp, C.L., Abdelaziz, A., Feuer, W.J. and Dubovy, S.R. (2012) Clinicopathologic Correlation of Ocular Surface Squamous Neoplasms at Bascom Palmer Eye Institute: 2001 to 2010. Ophthalmology, 119, 1773-1776. https://doi.org/10.1016/j.ophtha.2012.02.049

[4] Fazaa, B. and Kamoun, M.R. (2003) Xeroderma pigmentosum. Annales de Dermatologie et de Vénéréologie, 130, 69-73.

[5] Miller, G.R. (1965) Circumlimbal Carcinoma-In-Situ. Archives of Ophthalmology, 74, 66-68. https://doi.org/10.1001/archopht.1965.00970040068015

[6] Dib, S., Benhadouch, R. and Abdou, T. (2019) Management of Squamous Cell Carcinoma of the Conjunctiva in a Young Patient: Case Report. Journal Français 
d Ophtalmologie, 42, 387-390. https://doi.org/10.1016/j.jfo.2018.09.007

[7] Amoli, F.A. and Heidari, A.B. (2006) Survey of 447 Patients with Conjunctival Neoplastic Lesions in Farabi Eye Hospital, Tehran, Iran. Ophthalmic Epidemiology, 13, 275-279. https://doi.org/10.1080/09286580600801036

[8] Janin-Manificat, H., Gambrellearb, J., Mege-Lechevallier, F., Aptel, F., Beccat, S., Denis, P., et al. (2011) Conjunctival Epidermoid Carcinoma Revealed by a Chronic Limbic Corneal Ulceration. Journal Français d Ophtalmologie, 34, 108-112.

[9] Poso, M.Y., Mwanza, J.C. and Kayembe, D.L. (2000) Malignant Tumors of the Eye and adnexa in Congo-Kinshasa. Journal Français D'Ophtalmologie, 23, 327-332.

[10] Moussala, M., Mbakop, A., Mekongo, M.O. and Ndombe, P. (1998) Diagnostic tardif des tumeurs oculo-orbitaires et médecine traditionnelle au Cameroun à propos de 2 cas. Médecine d'Afrique Noire, 45, 22-26.

[11] Berete, C.R., Desjardins, L., Kouassi, L.J., Coulibaly, F., Kouakou, K.S., Gbe, K. and Fanny, A. (2016) Relationship between Human Immunodeficiency Virus (HIV-AIDS) and Conjunctival Squamous Cell Carcinoma (CEC): A Clinical Epidemiological Study of 26 Cases in the Ophthalmology Department of the University Hospital of Treichville-Abidjan (Abidjan-Côte d'Ivoire). Journal Français d Ophtalmologie, 39, 467-473. https://doi.org/10.1016/j.jfo.2015.09.016

[12] Acis, D., Donnio, A., Ayéboua, L., Richer, R., Guyomarch, J., Warter, A., et al. (2008) Conjunctival Squamous Cell Carcinoma. Four Cases Reported in the French West Indies. Journal Français d Ophtalmologie, 31, 533.e1-533.e5. https://doi.org/10.1016/S0181-5512(08)72472-0

[13] Secka, S.M., Agboton, G., Gueye, N.N., Diop, J., Seck, C.M. and Lam, A. (2015) Epidemiological and Clinical Characteristics of Primary Ocular Cancers in Blacks: Our Experience with 111 Cases. Journal Français d' Ophtalmologie, 38, 41-45. https://doi.org/10.1016/j.jfo.2014.06.007

[14] Denis, P., Charpentier, D., Roudier, M., Lemaire, J.C., Levin, N. and Nguyen Khoa, J.L. (1994) Conjunctival Squamous Cell Carcinoma and Human Immunodeficiency Virus. Journal Français d Ophtalmologie, 17, 366-369.

[15] Kaimbo Wa Kaimbo, D., Parys-Van Ginderdeuren, R. and Missotten, L. (1998) Conjunctival Squamous Cell Carcinoma and Intra Epithelial Neoplasia in AIDS Patients in Congo Kinshasa. Bulletin de la Societe Belge d Ophtalmologie, 268, 135-141.

[16] Chisi, S.K., Kollmann, M.K. and Karimurio, J. (2006) Conjunctival Squamous Cell Carcinoma in Patients with Human Immunodeficiency Virus Infection Seen at Two Hospitals in Kenya. East African Medical Journal, 83, 267-270.

https://doi.org/10.4314/eamj.v83i5.9432

[17] Pola, E.C. (2003) The Trend of Ocular Surface Squamous Neoplasia among Ocular Biopsies Submitted for Histology from Sekuru Kaguvi Eye Unit, Harare between 1996 and 2000. Central African Journal of Medicine, 49, 1-4.

[18] Elouarradi, H. and Bencherif, M.Z. (2014) Neglected Conjunctival Squamous Cell Carcinoma in a Case Report. The Pan African Medical Journal, 17, Article No. 226.

[19] Abdallah, E.S., Caml, L.S., Shields, J.A. and Ralph, M.D. (2003) Aggressive Conjunctival Squamous Cell Carcinoma in a Patient Following Liver Transplantation. Archives of Ophthalmology, 121, 280-282.

https://doi.org/10.1001/archopht.121.2.280 